\title{
Digital Diplomacy-Maximizing Social Media in Indonesia's Economic and Cultural Diplomacy
}

\author{
Syafruddin Pohan ${ }^{1}$, Hazairin Pohan ${ }^{2}$, Indah Nuria Savitri ${ }^{3}$ \\ Department of Communication Studies, Faculty of Social and Political Sciences ${ }^{1}$ \\ University of Sumatera Utara ${ }^{1}$ \\ Ministry of Foreign Affairs Republic of Indonesia ${ }^{23}$ \\ pohansyafruddin@yahoo.co.id, hazpohan@gmail.com, indahnuria@gmail.com
}

\begin{abstract}
As Indonesian foreign policy now focuses on the enhanced economic and cultural diplomacy in advancing its national interests, social media outlets certainly offer opportunities and advantages that are too good to be missed. This paper intends to portray the use of social media outlets in diplomacy and to demonstrate that, when their use responds to the audience's needs and strategically considers the overall information landscape, they can be utilized as effective public diplomacy tools. Comparative analysis about the current use of social media by the U.S. State Department and Indonesia's Ministry of Foreign Affairs will provide more complete pictures of valuable contribution, as well as challenges and possible risks, of the use of social media in enhancing public diplomacy, including economic and cultural diplomacy.The conclusion of this study: (1) digital diplomacy is not a replacement for face-to-face diplomacy, but rather a complement to it. Social media serves as one of the catalysts which expedite the desired changes on the ground. Certainly, (2) social media alone cannot cause revolutions or social movements, but it has proved to be an effective tool for strengthening and amplifying the message we want to deliver, (3) in the case of economic and cultural diplomacy, social media fits in well.Taking all the aforementioned development into consideration, it is therefore timely to take a closer look and conduct a critical review of maximizing social media and digital diplomacy platforms and integrate them into Indonesia's diplomatic practices.

Keywords: Social media, digital diplomacy, Indonesia's Economic and Cultural Diplomacy.
\end{abstract}

\section{INTRODUCTION}

As the robust advance of information and communication technologies (ICT) continue to enable and facilitate people around the globe to connect and to interact directly with one another, social media outlets have stolen the attentions of many bureaucrats for their major role in voicing peoples' aspirations and shaping public policies in many areas.Along with the exponential growth of social media around the world, many government officials, including diplomats, have utilized this channel to conduct and expand their public diplomacy.

While security and political issues are still considered sensitive and tend to be handled in more traditional ways, many foreign ministries expand their public diplomacy efforts focusing on social, economy and cultural exchanges through social media.Rigorous dissemination of information of one country's values and cultures has been aggressively conducted in these platforms.

Nevertheless, as this new technological revolution is bearing down on foreign ministries, it proves to be difficult for many. The slow pace of adaption in digital diplomacy by many foreign ministries suggests that there is a degree of uncertainty over this novel concept. Perhaps, two of the biggest questions here are what digital diplomacy is and what it can be used for. In addition, how to effectively formulate and implement communication strategies using these new platforms. 
At this juncture, one particular foreign ministry has been considered successful in embracing these novel technologies. The U.S. State Department has been known as "the world's leading user" of e-diplomacy or some might say, internet diplomacy. The U.S. State Department, including its representatives and missions abroad, has been strategically using websites and technology-basedvenues to help carry out its diplomatic affairs.

Along the same line, the European Union continues to adapt its policies and approaches in dealing with the world's affairs and responding to the exponential growth of social media. Some ASEAN member countries,such as Thailand and the Philippines, are also on the front lines when it comes to digital diplomacy.Indonesia, to some extent, has also joined the game and made use of these latest technologies.

As Indonesian foreign policies are now centering on the enhanced economic and cultural diplomacy in advancing its national interests, social media outlets certainly offer opportunities and advantages that are too good to be missed.

This paper intends to portray the use of social media outlets in diplomacy and to demonstrate that, when their use responds to the audience's needs and strategically considers the overall information landscape, they can be utilized as effective public diplomacy tools. Comparative analysis about the current use of social media by the U.S. State Department and Indonesia's Ministry of Foreign Affairs will provide more complete pictures of valuable contribution, as well as challenges and possible risks, of the use of social media in enhancing public diplomacy, including economic and cultural diplomacy.

It is important to note that digital diplomacy is not a replacement for face-to-face diplomacy, but rather a complement to it. Social media serves as one of the catalysts which expedite the desired changes on the ground. Certainly, social media alone cannot cause revolutions or social movements, but it has proved to be an effective tool for strengthening and amplifying the message we want to deliver. And in the case of economic and cultural diplomacy, social media fits in well.

Taking all the aforementioned development into consideration, it is therefore timely to take a closer look and conduct a critical review of maximizing social media and digital diplomacy platforms and integrate them into our diplomatic practices.

\section{AIMS OF THE RESEARCH}

In conducting the critical review, this paper aims to:

Assess the development of digital diplomacy, particularly the rise of social media as a new frontier of diplomacy. The paper will also give a brief overview on information and communication technologies, the global status of internetavailability as well as the changing nature of diplomacy, assess and comparatively analyze the use of social media by ministries of foreign affairs and diplomats, particularly the U.S. and Indonesia, in conducting public diplomacy, identify and take stock of strengths and weaknesses, as well as contemporary challenges and opportunities faced in utilizing social media outlets for expanding public diplomacy, which will be used as the basis for policy recommendations.

\section{Social Media and Diplomacy}

On November 7, 2012, the world watched the US presidential election. As the election process was rolling, people around the world followed the progress, particularly the quick count, through their televisions, radio stations, and websites. Some checked their Facebook or Twitter accounts to 
post comments, thoughts, and even hopes on the election, or simply to get detailed information on the ongoing election. As Barack Obama won, social media outlets were once again bombarded by new status, statistics, comments, analysis and more information regarding this important event.

Along the same line, on September 25, 2012, the President of Indonesia, SusiloBambangYudhoyono, addressed the United Nations General Assembly in New York in its 67th session with strong messages related to the world's peace and prosperity. At the very same time, through special channel named the UN Webcast, many of us, including the author, from many different parts of the world, were witnessing exactly the same event.

Perhaps, for many of us, watching a real-time show or event happens in one place while being separately thousands of miles away, was nothing out of ordinary. Thanks to the Internet, or some might generally refer as information and communication technology (ICT), onethird of the world's populations is now able to enjoy this privilege.

Since being introduced in, arguably, 1974,1 the internet has brought many significant changes to the world. Those changes, both positive and negative, range from simple connections with family and friends to revolutionary movements that change the life of nations, from online shopping to cybercrime. The rapid development of ICT has enabled people to better connect and communicate with one another,

\footnotetext{
${ }^{1}$ Many sources have provided different timeline when it comes to the history of internet. One argued that the internet was firstly developed in 1957, while others offer that the internet was firstly used in public in 1974

"When was the internet invented?" (Accessed on 28 October 2012) http://www.letusfindout.com/ when-was-the-internet-invented/.
}

regardless of time difference and geographical locations. Information is abundant and easy to access, providing more exposure on myriads of issues around the globe for everyone.Indeed, various developments in political, economic, social and cultural areas have taken place with the help of Internet

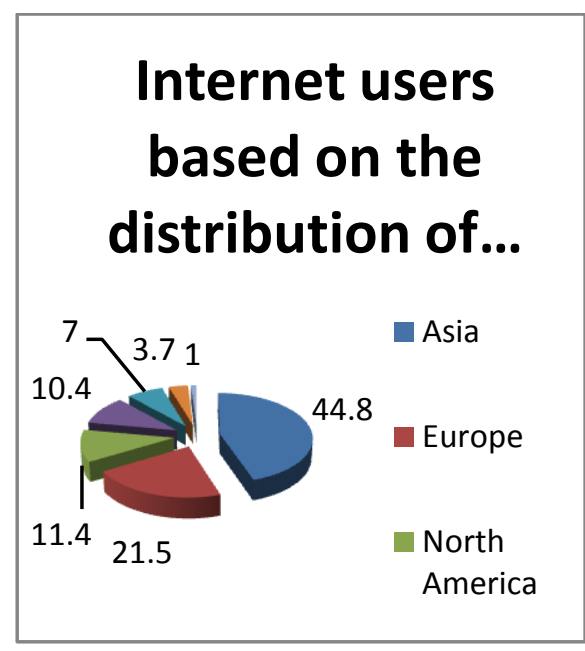

Chart 1: Internet users based on the distribution of world regions

Source: The world in 2011: ICT Facts and Figures (www.itu.int)

Indonesia, on its part, is certainly part of the top 20 countries with the highest number of internet users. As Internet initially introduced in the 1990s in Indonesia, ${ }^{2}$ this country is now positioned at number 8 , contributing $2.3 \%$ of the total world's internet population amounting 55.000.000 people. From the same list, the only ASEAN member country which makes the top 20 is the Philippines, with approximately 33.6 million people using internet actively. ${ }^{3}$

\footnotetext{
${ }^{2}$ David T. Hill and KhrisnaSen, "The Internet in Indonesia's New Democracy", Democratization Vol 7 (1), 2000, pp. 119 - 136,(Accessed 18 October 2102) in http://www.tandfonline.com/doi/abs/10.1080/1351 0340008403648\#preview.

${ }^{3}$ The top 10 countries in the list of top 20 countries comprises China at number 1, with approximately $538,000,000$ users ; 2. United States with $245,203,319$ users ; 3 . India, with $137,000,000$
} 
This paper will now then focus on one of the most ground-breaking innovations in information and communication technologies, social media.

2. Defining Information and Communication Technologies Latest Trends: Social Media Outlets

Amidst the continuously evolving ICT, one of the highlights of this cutting-edge technology is the development of social media. Being recognized as ubiquitous software connecting social actors to interact in public spheres, social media outlets have been the darlings of information and communication technology thus far. Also commonly known as social network sites or technologies, social media can also be described as "webbased services that allow individuals to (1) construct a public or semi-public profile within a bounded system, (2) articulate a list of other users with whom they share a connection, and (3) view and traverse their list of connections and those made by others within the system." 4

Kaplan and Haenlein $(2010)^{5}$ further describe social media as "a group of Internet-based applications

users; 4. Japan, with 101,228,736 users ; 5. Brazil, with $87,276,099$ users ; 6 . Russia, with $67,982,547$ users ; 7. Germany, with $67,483,860$ users; 8.Indonesia, with $55,000,000$ users; 9.United Kingdom with 52,731,209 users ; and 10. France, with 52,228,905 users . (Accessed 28 October 2012) In http://www.itu.int.

${ }^{4}$ Danah M. Boyd and Nicole B. Elisson, Social Network Sites: Definition, History, and Scholarship. Journal of Computer-Mediated Communication Vol. 13(2008) pp. 210 - 230, (Accessed 5 October 2012) in http://jcmc.indiana.edu/vol13/issue1/ boyd.ellison.html.

5 Andreas M. Kaplan and Michael Haenlein, "Users of the world, unite! The challenges and opportunities of Social Media," Business Horizon Vol. 53, issue 1, January-February 2010, pp. 59 68 (Accessed $18 \quad$ October 2012) inhttp://eee.sciencedirect.com/ science/article/pii/S0007681309001232 that build on the ideological and technological foundations of Web 2.0, and that allow the creation and exchange of user-generated content." Web 2.0 here refers to the "second generation of services in the world wide web which enable people to collaborate and share information online", emphasizing on the interactivity nature of the connection among the users. Moreover, usergenerated content can be defined as "any data and media that is contributed by the users of the websites", where users here can simply be anybody.It also means that any particular ideas or views from any individualscan be offered and made available online. Organization for Economic Cooperation and Development (OECD) further specifies criteria of user-generated content, which include the availability of the content(s) on a publicly accessible website or on a social networking site; the minimum creative efforts induced in the content(s); and the creation of the content(s) outside of professional routines and practices. ${ }^{6}$

Some have classified social media technologies and tools into several types and forms, which, among others, consist of electronic magazines, Internet forums, weblogs, social blogs, micro blogging, wikis, social networks, podcasts, photographs or pictures, video, rating and social bookmarking. ${ }^{7}$

Amidst the growing numbers of social media outlets, Kietzmann et al. ${ }^{8}$ further define how those outlets differ

\footnotetext{
${ }^{6}$ Organisation for Economic Co-operation and Development (OECD), "Participative Web and User-Created Content: Web 2.0, Wikis and Social Networking" Vol. 18 (2007).

${ }^{7}$ Danah M. Boyd and Nicole B. Elisson, ibid.

${ }^{8}$ Jan H. Kietzmann, Kristopher Hermkens, Ian P. McCarthy, Bruno S. Silvestre, "Social media? Get serious! Understanding thefunctional building blocks of social media", Business Horizon (2011) Vol. 54, pp. $241-251$, In http://business.sfu.ca//Files/PDF/research/2011 So cial_Media_BH.pdf
} 
from one another. Based on the extent to which they are focusing on, there are seven functional blocks which characterize social media outlets, namely identity; conversations; sharing; presence;relationships; reputation; and groups.

Social networking sites, which refer to versatile sites where people can share text, pictures, video, audio files and myriads of applications. Facebook and Twitter are among the most popular social networking sites.

Virtual game world, which enable users, - or rather gamers, to connect to one another while playing the same game application.World of Warcraft, Farmville, and Mafia Wars fall under this category.

virtual social worlds, for example Second Life.

Nevertheless, many of these services can be integrated via social network aggregation platforms, combining many useful functions into one site. No wonder social media network websites like Facebook, Twitter, Bebo and MySpace gain popularity in no time. Even local social media services such as China's micro blogging site, SinaWeibo, continue to enjoy growing attentions from users.

Another crucial development here is the robust usage of mobile social media, which refer to the samesocial media applicationstraditionally running on computers or laptops, but used on mobile devices. Along with almost 6 billion mobile-cellular subscriptions and 1.2 billion active mobilebroadband subscriptions, ${ }^{9}$ the use of

\footnotetext{
${ }^{9}$ From the World in 2011 - ICT Facts and Figures (International Telecommunication Union, 2011), it is estimated that out of 7 billion global population, one-third is online already. Developing countries, led by China and India, are now contributing approximately $62 \%$ of the world's total number of internet users. Mobile-cellular subscriptions also enjoy a stable increase where in 2011, 5.9 billion people have subscribed to mobile-cellular accounts. Meanwhile, mobile-broadband
}

mobile social media is exponentially increasing. ${ }^{10}$ With internet everywhere' packages for cellular getting cheaper and more accessible in many parts of the world, many users are able to get access to their social media accounts, displaying a higher location- and time-sensitivity which certainly expedite the spread of information.

With the tremendous growth and significant impacts derived from social media in many areas, experts and scholars continue to analyze their potential roles. Some theoretical reviews have been submitted, including from Clay Shirky, New York University professor. He suggests that social media is an important new tool for promoting social and political change, serving as a catalyst for significant political change. He further argues that social media "has revolutionized how people form political opinions and has made information so widely accessible that more people than ever are able to develop considered points of view."11

As this paper will focus on the use of Facebook and Twitter in diplomacy, it is worth taking a closer yet brief look at the historical development of these two phenomenally popular social media outlets.

\section{1). Facebook}

Founded by Mark Zuckerberg, with his college roommates and fellow Harvard University students Eduardo Saverin, Andrew McCollum, Dustin Moskovitz and Chris Hughes, Facebook was launched in February 2004. Initially, Facebook membership was

subscriptions have grown $45 \%$ annually in the course of recent four years. In 2011, active mobilebroadband subscriptions have reached almost 1.2 billion, which is twice as many as fixed-broadband subscriptions which cover 600 million households worldwide.

${ }^{10}$ International Telecommunication Union, ibid.

${ }^{11}$ Clay Shirky, "The Political Power of Social Media”, 90 Foreign Affairs 28, pp. 28 - 29. 
set limited for Harvard students, but then was expanded to other colleges in the Boston area, the Ivy League, and Stanford University. With a growing support from its users, Facebook founders decided to launch the highschoolversion and to extend the memberships to employees of several companies. Finally, in September 2006, it allowed everyone of age 13 and older with a valid email address to register for a Facebook account. 12

As registered Facebook members, users can create profile page and share information with unlimited number of other users or virtual 'friends'. Although 'friends' are usually those known by the users in real life and thus invited and/or added to the friends' list, some users choose to approve without having the 'real' connections in order to expand their circles of friends.

Another choice of expanding the network in this site is by creating pages which can catch the attention of unlimited 'fans', users who are interested to the content but not necessarily have to be friends or approve friends' invitations. Privacy settings are also available, putting the control in the hands of its users. ${ }^{13}$ Users are able to create a specific page and now, Facebook has 'sponsor' service where users can sponsor or advertise particular event or product with as cheap as 50 cent USD per item.

Until recently, the United States is still the home of most active Facebook users, with close to 156 million active users, or approximately $65 \%$ of Facebook's entire global

\footnotetext{
${ }^{12}$ Sarah Phillips, "A brief history of Facebook". The Guardian (London). Retrieved March 7, 2008, in $\quad \mathrm{http}: / / \mathrm{www}$. guardian.co.uk/technology /2007/jul/25/media.newmedia.

${ }^{13}$ Sarah Joseph, "Social Media, Political Change, and Human Rights,"35 B.C. Int"l\& Comp. L. Rev. 145 (2012), http//lawdigitalcommons.bc.edu/iclr/vol35/iss1/3.
}

audience. Brazil is now Facebook Nation No.2, while India rank at number $3 .{ }^{14}$

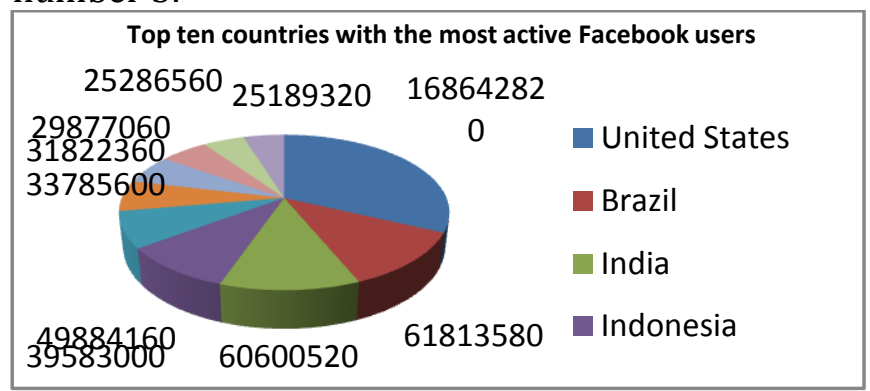

Chart 2: Top Ten Countries with the most active Facebook users as of November 2012

(Sources: www.checkfacebook.com, 2012)

Indonesia is undoubtedly experiencing social media 'booming' since the advance development of ICT has enabled wider constituents to have access to the internet. Coupled with the overall progress in economy, more Indonesians now have computers, laptops, tablets, smart phones and similar devices, with internet connection.No wonder Indonesia now ranks number four as the world most active Facebook, listing 49,884,160 users. ${ }^{15}$

At this juncture, Facebook, which is available in 70 languages, has reached 1 billion active users by September 14, 201216. This impressive statistic is projected to rise as Facebook still successfully attracts

\footnotetext{
14 According to www.checkfacebook.com, as of June 2012, real-time rankings for countries with the most active Facebook are as follows: 1. United States, with $168,642,820$ users;2.Brazil, with $61,813,580$ users; 3 . India, with $60,600,520$ users; 4. Indonesia, with 49,844,160 users; 5.Mexico, with 39,583,000 users;6.United Kingdom, with 33,785, 600 users; 7. Turkey, with 31,822,360 users;8.Philippines, with $29,877,060$ users; 9.France, with 25,286,560 users; and 10.Germany, with $25,189,320$ users.

${ }^{15}$ www.checkfacebook.com, ibid.

16 "Facebook Tops Billion-User Mark", the Wall Street Journal (Dow Jones), (Accessed October 4 2012), in http://online.wsj.com/article/ SB10000872396390443635404578036164027386 112.html
} 
people's attention with wide range of services it offers, starting from simple birthday reminder to sophisticated game applications.

\section{2). Twitter}

Twitter, on the other hand, is a micro-blogging site which allows users to post comments, status, information and any text-based content not more than 140 characters, or widely known as "tweet". Surprisingly, a wide variety of information has been broadcasted through Twitter, which also include links to articles, photos, pictures, videos and audio streams.Tweets are immediately visible to "followers", those who have registered and requested to follow certain user(s). Unlike Facebook and its circles of "friends", Twitter users can follow any other user and most tweets are available for public. Of course, all users have the choices to unfollow or block other users from getting access to the feed, giving them the power to control their audiences.

Other interesting features in Twitter are the "retweet" and "quote tweet" functions, permitting users to easily and expeditiously distribute any information to the world-wide audience. "Hashtags", another unique facet of Twitter, allow users to search for trending topics as tweets are organizedon certain topic. ${ }^{17}$ For example, \#Indonesia will make people find tweets on that topic easily.

In Twitter technologies, "mentions" are a specific menu that links users to other specific users, by typing the profile name preceeded by the @ symbol. All posts attributable to that account will appear on other users' "feed" and this will immediately attract their attentions. The simplicity of some of the abovementioned technical features unique to Twitter has contributed positively to the

\footnotetext{
${ }^{17}$ Sarah Joseph, Ibid.
}

growing numbers of its account holders.

Until recently, from the top 10 countries with the most Twitter accounts list, United States stays at number 1, with recorded 141.8 million accounts. Brazil follows on the second spot, with 41.2 million accounts, and Japan at number three with 35 million accounts.32.2 million accounts, while Indonesia stays at number 5 with 29.4 million accounts. ${ }^{18}$ In terms of active Twitter users, surprisingly, China champions the list with approximately 33.5 million active users, despite the fact that the Chinese Government blocks this service. ${ }^{19}$

Indonesia ranks number five in the world, contributing $15 \%$ of the overall tweets. It was estimated that 3.8 million Indonesians, particularly Jakartans, are actively tweeting and posting approximately 53.880 tweets per hour. Unsurprisingly, Jakarta is the most active city where tweets were posted, surpassing Tokyo, London, Sao Paolo and even New York, respectively. Meanwhile, Bandung stays at number six on the list. ${ }^{20}$

As noticeably showcased in the Arab Spring phenomenon where the term "Twitter Revolution" was ubiquitously coined, this site is now deemed as one of the extremely influential sources of real-time news. ${ }^{21}$

\footnotetext{
${ }^{18}$ Twitter reaches half a billion accounts, More than 140 millions in the U.S., (Accessed November 2, 2012), in http://semiocast.com/publications/2012_07_30_T witter_reaches_half_a_billion_accounts_140m_in_ the_US

${ }^{19}$ Shea Bennet, REVEALED: The 10 Countries With The Most Active Twitter Users, 24 September 2012, (Accessed 1 November 2012), in http://www.mediabistro.com/alltwitter/twittercountries-active-users_b28908

${ }^{20}$ Shea Bennet, ibid.

21 Blake Hounshell, The Revolution Will be Tweeted, Foreign Policy, July 2011, at 20, (Accessed $20 \quad$ October 2012), inhttp://www.foreignpolicy.com/articles/2011/06/2 0/the_revolution_will_be_retweeted.
} 
The Changing Nature of Diplomacy - A Theoretical Review

As public diplomacy and strategic communications experts continue to explore the potential of the relatively new social media, one cannot deny the changing nature of the world of diplomacy. The marvel of information and communication technology has significantly impacted the conduct of diplomacy, which traditionally centered on government officials and took place behind the close doors.

Although many argue that ICT is only a tool which facilitates the overall business, but the changing nature of diplomacy is inevitable. New technologies are impacting the policies and changing the landscape of diplomacy, governance and international relations.

Alongwith the development of new communication means and tools, we have seen novel approaches involving information and communication technologies introduced and implemented in the conduct of diplomacy. Websites, social media outlets, and live-chats are now among the common platforms used by ministries and government agencies.

Here, the significant need of networking is also highlighted. Although it has been long recognized as one of the prerequisites of good diplomacy, but the way diplomats expand their networks are also evolving along with the advances of ICT. Some can argue that traditional venues such as formal meetings and functions like diplomatic receptions will serve this purpose, but ICT has proven to facilitate more acquaintances and sustain the relationships. ${ }^{22}$

Another development in the traditional conduct of diplomacy that is

\footnotetext{
${ }^{22}$ Owen Henry, ibid.
}

relevant here is multi-track diplomacy. Initially introduced in the form of "Track Two Diplomacy" by Mr. Joseph Montville in the 1980s, the conceptual way to view the process of diplomacy continues to evolve. In 1991, Louise Diamond and John W. McDonald submitted multi-track diplomacy, which consists of nine tracks, namely government (1); Non-Governmental Organizations (NGOs)/professionals (2); business (3); private citizens (4); research, training, and education (5); activism (6); religion (7); funding (8); and communication and the media (9). ${ }^{23}$

Clearly, the conduct of diplomacy now involves many actors and stakeholders other than the diplomats or government officials. These many facets of diplomacy have to be managed and again, the evolution of public diplomacy includes the use of powerful new tools, social media outlets, to connect cultures, increase awareness, and advocate policy positions.

In the networked age where transparency and accountability are highly demanded, the growing desire of governments all over the world to have "two-way-dialogue" with their constituencies, whether it is at national, regional as well as international level, can be catered by social media.

The European Union, which is the home of roughly 150 million of Facebook users, has also embraces digital diplomacy, with European External Action Service (EEAS) as the spearhead of EU's public diplomacy. Creating Facebook page since May 2011 and maintaining two Twitter

\footnotetext{
${ }^{23}$ What is multi-track diplomacy?, The institute for Multi-Track Diplomacy, (Accessed November 5, 2012), inwww.imtd.org/at-aglance/mission/working-methods/what-is-multitrack-diplomacy
} 
accounts, EEAS continues to improve its engagement through social media. ${ }^{24}$

If we analyze further, there are three main reasons why social media has been successfully chosen as the new frontier of diplomacy. Firstly, social media enables us to directly engage with citizens around the world. With millions of subscribers from almost every corner of the world, social media can facilitate the network expansion and make public diplomacy effective. Second, sharing information in real-time and on global scale can be easily done. User-friendly technologies and down-to-earth approach used in social media make the dissemination process easier, faster, and farther. Third, intensive communication with extensive networks in social media enables us to understandpeople and events more deeply, giving us a more comprehensive picture of public's aspirations and perspectives. Therefore, further analysis on the information received through social media will be the best use of it.

However, there are some limitations as well. We cannot deny that the slow pace adaptation to digital diplomacy by many foreign ministries suggest that there is a degree of uncertainty over what digital diplomacy is and its potentials. It can be a rude awakening for governments as digital diplomacy requires transparency, where some countries still restrict the internet connection for their citizens. At some point, loss of control due to public demands is the risks governments must be willing to take. In additions, the use of social media outlets do not always yield benefits, as people do have illicit and

24 Megan Kena, "Social Media: following EU public diplomacy and friending MENA", Policy Brief, European Policy Centre, July 2011,(Accessed 15 November 2012) in http://hawk.ethz.ch/serviceengine/files/ISN/14149 8/epublicationdocument_singledocument/ 55edfa45-e002-4363-ac6a-

292ccfd9042b/en/pub_1320_social_media.pdf ill-fated purposes while using them. Eculture among people also varies, resulting in different level of acceptability and responsiveness towards contents distributed through social media outlets.

It is also important to note that digital diplomacy is not, and is never meant to be, a replacement of face-toface diplomacy. It, in fact, builds on traditional statecraft, incorporating the new technologies, demographics and networks of the modern era. Social media is just a new means, new instrument, for advancing the same end which is built on the traditional government-to-government connections.It is indeed too naïve to believe that meaningful relationships with and among people can be built through social networking media only. Therefore, virtual interactions need to move forward in order to get real substantive gains in diplomacy.

3. Winning the Heart and Minds of Peoples through Social Media: the Case of the United States of America

Many argue that the United States State Department is "the world's leading user of e-diplomacy", using the apparent role of social media in conducting their public diplomacy and extending their policies as well as influences. Now, there are 25 separate e-diplomacy nodes operating at the State Department Headquarter in Washington D.C., employing over 150 employees, while around 935 overseas staff employing e-diplomacy communication tools. ${ }^{25}$

In 2006, during the Secretary of State Condoleezza Rice period, 'virtual posts' were set up so that people can visit "a website and chat

25 Fergus Hanson, "Revolution @State: The Spread of EDiplomacy", Lowy Institute for International Policy, (Accessed November 1 2012) in http://www.lowyinstitute.org 
online with U.S. Diplomats."26 Transformational Diplomacy was introduced and following this step, the first State Department blog entry was posted on the OpinioJuris blog in January 2007 by John Belinger III, senior legal advisor. In October the same year, Dipnote, the State Department official blog on public diplomacy was officially launched. ${ }^{27}$

These strategies were further strengthened as President Obama signed "Transparency and Open Government: Memorandum for the Heads of Executive Departments and Agencies" on January 21, 2009. Emphasizing on the use of Web 2.0, this Memorandum outlined, among others, the Administration's desire to tap into the knowledge of global communities, while at the same time share and expand the U.S. policies and influences. ${ }^{28}$

The appointment of Judith McHale, former President and the CEO of Discovery Communication, - a global giant company with 1.4 billion subscribers in 170 countries and 35 different languages, as the Under Secretary of State for Public Diplomacy and Public Affairs (now this position is

26 Farah Stockman, "U.S. to Shifts Envoys to Developing Countries, "The New York Times", January 19, 2006, (Accessed 6 November 2012)) in

http://www.nytimes.com/2006/01/19/world/americ as/19iht-diplo.html

27 Ben Bain, "State Department Opens Up with Dipnote Blog," Federal Computer Week, September 27, 2007,(Accessed November 1 2012) in http://fcw.com/articles/2007/09/27/statedepartment-opens-up-with-dipnote-blog.aspx

28 "Transparency and Open Government:

Memorandum for the Head of Executive

Departments and Agencies", the White

House, January 2, 2009,(Accessed 3

November 2012) in

http://www.whitehouse.gov/the-

_press_office/TransparencyandOpenGovern ment held by Ms. Tara D. Shonenshine), reinforced the President's commitment in advancing the U.S. public diplomacy.

One poignant example of this is the mass distribution of A New Beginning, President Obama's speech in Cairo on June 4, 2009, through a wide variety of Internet applications, including social media outlets, podcasts, as well as a live Webcast on the official White House's website. Fully funded by the State Department, besides formal channels traditionally used by this institution, the speech and its link were available on YouTube, Facebook, Twitter and MySpace, including its translations in Arabic, Farsi, Urdu and eight other languages. Estimates say that the speech was spread in more than 200 countries and related text-message as well as tweets reached more than 20,000 users worldwide. 29

As more creative models of active engagement with public through social media outlets are further developed, the U.S. State Department held a live global Twitter Q\&A with the Under Secretary of State for Public Affairs and Public Diplomacy, Tara Sonenshine, in June, 2012.Issues ranging from human rights to violentacts in some parts of the world, as well as the U.S. social cultural programs were questioned, where around 16 million people worldwide were engaged..$^{30}$

${ }^{29}$ Roy Furchgott, "State Department to Text Obama Speech, " The New York Times, June 3, 2009, (Accessed 1 november 2012) inhttp://gadgetwise.blogs.nytimes.com/2009/ 06/03/voice-of-america-to-become-texts-ofamerica

${ }^{30}$ Victoria Esser, "Digital Diplomacy: A New Frontier of Diplomacy or Simply a Delusion?", September 24, 2012, (Accessed 3 November 2012) in http://www.globalasia.org November 5, 2012 
Furthermore, President Obama issued a directive entitled "Building a 21st Century Digital Government" on May 23, 2012.As a result, comprehensive Digital Government Strategy was launched, aiming at, among others, delivering better digital services to the American people. Social networking sites are also part of the platforms. ${ }^{31}$

The U.S. Government has decided to take greater advantage of a domestic technological innovation, particularly social media sites.In addition to the establishment of the Office of e-Diplomacyin 2003; the use of internal unclassified online encyclopedia called Diplopedia; the official blogging site, Dipnote; and ExchangesConnect, a cultural exchange social networking site, theState Department also actively engages with public by utilizing Facebook, Twitter, YouTube, Google +, Flickr, Tumblr and various social media outlets. This paper intends to take a closer look at and limit the observation to the activities in Facebook and Twitter account.

In Twitter, several relevant accounts have been registered, classified into three big groups: agency accounts, such as the U.S. State Department itself, USAID, and USAF Band; embassy accounts, such as the U.S. Embassy in Jakarta, Cairo, London and many others; and individual practitioner accounts, which include Secretary of State, Hillary Clinton andUS Ambassador to Indonesia, @StateDept is the official account the U.S. State Department in Twitter.

Representing the base of U.S. Diplomacy, @StateDept tweets on a

${ }^{31}$ Digital Government Strategies, (Accessed 3 November 2012) in http://www.state.gov/digitalstrategy/index.ht $\mathrm{m}$ variety of matters of state diplomacy. A wide range of issues, starting from simple wishes forNational Day to strong content output,-mostly in the forms of direct links, about political affairs are broadcasted. Relevant information from its sub-agencies, such as USAID, is also 'retweeted' or republished. By the time of this writing, @StateDept has 26,423 tweets and 383,085 followers. Similarly, @usembassyjkt is officially managed by the U.S. Embassy in Jakarta.

Producing 12,358 tweets and being followed by 67,638 users, @usembassyjkt mostly broadcasted issues related to social, cultural issues and people-to-people contacts. Quizzes and door prizes are also regularly held, providing additional incentives and attracting more followers and retweet. Issues such as the latest presidential election, the visit of President Obama to Jakarta and choosing school in the U.S. have been amusingly packed, inviting more and more followers of this page.

At this moment, the U.S. State Department does not register and control an official organizational account in Facebook. However, most of the related Facebook accounts are registered and managed by the U.S. embassies abroad, including in Jakarta, Indonesia. In fact, Facebook account for the U.S. Embassy in Jakarta has been acknowledged as one of the leading examples of successful use of social media in engaging local people and advancing the U.S. interests in Indonesia. One simple example is the outreach program conducted by the U.S. Embassy in Jakarta prior to the visit of President Barack Obama to Indonesia in $2010 .{ }^{32}$ ${ }^{32}$ Melanie Ciolek, "Understanding Social
Media's Contribution to Public Diplomacy
:How Embassy Jakarta's Facebook Outreach
Illuminates the Limitations and Potential for
the State Department's Use of Social Media,"
(Accessed 2 November 2012), in 


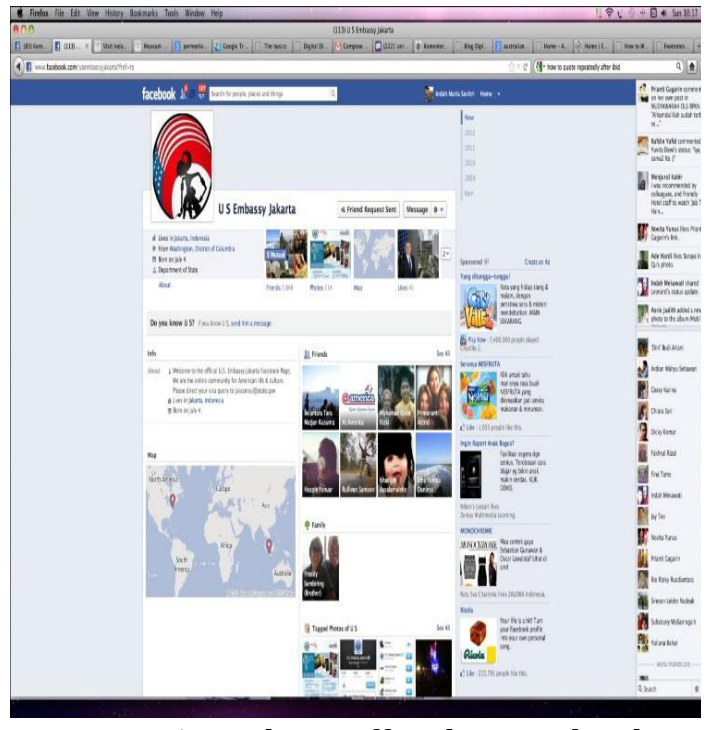

Picture 1: The official Facebook account of the U.S. Embassy in Jakarta (source:http://www.facebook.com/us embassyjakarta?fref=t)

However, drawbacks and constraints do persist in using social media to disseminate public diplomacy campaigns. Not everybody likes the U.S. foreign policies towards certain issues. Those views are also broadcasted and tweeted freely. As public can have the same access, some 'unpleasant' or irrelevant comments are received and have the potentials to divert or even destruct the interactive process and messages previously set. Besides, as previously mentioned, different landscape of information communities and e-culture of people in various countries significantly impact the responses and acceptability of policies being distributed through social media. What works well in Indonesia does not apply in Iran or Turkmenistan, for example. Moreover, in some countries, governments do restrict the open access of internet for their peoples which hinder them from

http://www.uscpublicdiplomacy.org/pdfs/mci olek_socialmedia_indonesia.pdf receiving information from the outside world.

4. Indonesia's Diplomacy in the Digital Era.

With new information and communication technologies being rigorously used in various aspect of life, including diplomacy, the Ministry of Foreign Affairs of Indonesia,hereinafter refer to as Kemlu, has joined the crowd as well.

As public diplomacy continues to be one of the missions of Kemlu, policies and programs which create and support Indonesia's positive image will persistently be strengthened. Moreover, economic diplomacy, which is generally referred to as the conduct of diplomacy using economic leverages, policies and measures to achieve national goals, and cultural diplomacy, where "exchange of ideas, information, values, systems, traditions, beliefs, and other aspects of culture, with the intention of fostering mutual understanding," 33 should ideally be supported by all elements and venues of diplomacy, including through social media outlets.

Along with the internal institutional reform taking place since 2001, Kemlu has established two prominent directorates in this case, Public Diplomacy as well as Information and Media Directorates, under the auspices of the Directorate General of Information and Public Diplomacy (previously known as Directorate General of Information, Public Diplomacy and International Treaties).

As stipulated in the Minister for Foreign Affairs Regulation Number 7/2011, Public Diplomacy Directorate is in charge of harnessing public

\footnotetext{
${ }^{33}$ The American political scientist and author, Dr. Milton C. Cummings, offers this profound definition of cultural diplomacy, as cited by the Institute of Cultural Diplomacy, available at http://www.culturaldiplomacy.org

/index.php?en_culturaldiplomacy
} 
support at home as well as abroad towards the implementation of Indonesia's foreign policies in the area of political, security, economic, development, social and cultural, as well as other strategic and emerging issues. It is equipped with five relevant sub-directorates, namely political and security; economics and development; social cultural; current and strategic issues; as well administrative division. ${ }^{34}$

Moreover, Information and Media Directorate is responsible for taking necessary measures in the field of information and media, particularly regarding news, multimedia, data, media facilitation, audiovisual, and publishing, which will establish Indonesian positive image and shape positive public opinion supporting Indonesian national interests abroad. It has six sub-directorates, namely news; multimedia; media data; mass media facilitation; audiovisual and publishing; and administration.

In this connection, multimedia sub-directorate is carrying out multimedia information management and development of Kemlu's website, including, among others, in preparing, coordinating, and implementing policies and programs in this field. Formulation of standards, norms, guidelines, criteria and procedures in the field of information and media also falls under this sub-directorate. With this mandate, Information and Media Directorate is indeed one of the spearheads of Kemlu's digital diplomacy. ${ }^{35}$

In addition to traditional ways and media in conducting public diplomacy, various novel information

\footnotetext{
${ }^{34}$ Minister for Foreign Affairs Regulation Number 7 Year 2011 on the Organization and Procedures in the Ministry of Foreign Affairs, Articles 680699, available in http://pih.deplu.go.id/smd/php/vis_doc_file.php?id $=4078$.

${ }^{35}$ Minister for Foreign Affairs. Ibid. Articles 656679.
}

and communication channels have been utilized by Kemlu, including official websites, Facebook and Twitter accounts. The official website of Kemlu, for example, has been established since 2002. Beside better displays and more user-friendly menu, further improvement is continuously conducted, including by integrating websites of Indonesia's 131 missions abroad, which consist of 95 embassies, 3 permanent missions, 30 consulate generals and 3 consulates. ${ }^{36}$

New menu, such as diplomatic blogs, has been added since October 9 , 2009. Displaying 33 notes until the time of this writing, a wide range of topics from political to social cultural issues as well as ASEAN dynamics to protection of Indonesian citizens abroad have been expressed through creative writings. ${ }^{37}$

Success stories of Indonesian citizens and related stakeholders abroad are also exhibited, ${ }^{38}$ and updated information on career and scholarships, including on internships in Kemlu, job vacancies in international organizations, are also available. Furthermore, online public services such as visa and consular service, diplomatic facilities and media services, are also available on the website.

\footnotetext{
${ }^{36}$ HartyoHarkomoyo, Assistant Deputy Director for Information Management on Multilateral Issues, November 10 and 17, 2012, telephone interviews

${ }^{37}$ Blog Diplomatik, (Accessed 8 November 2012) in http://blog.kemlu.go.id

${ }^{38}$ Success Story, (Accessed 8 November 2012) in http://www.kemlu.go.id/Pages/Achievement.aspx? $\mathrm{l}=\mathrm{en}$
} 


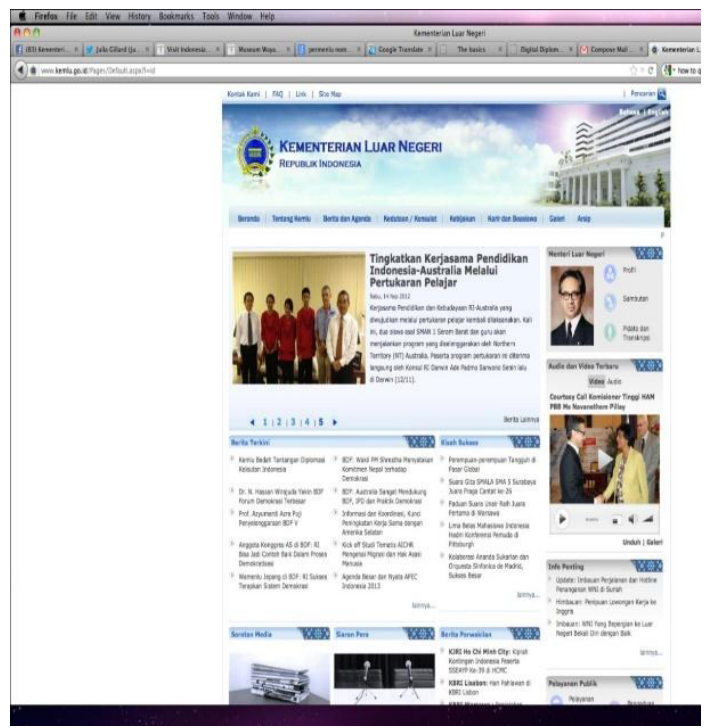

Picture 2: Kemlu's homepage (source: http://www.kemlu.go.id)

Despite the fact that formal policies on the use of social media in conducting diplomacy are yet to be developed, Kemlu has managed to create its official Facebook account and page since June 2010.Until the time of writing (November 2012), 5,995 individuals 'like' it, while 66 has 'talked' about it. Many issues, in the forms of status, links, and photos, have been raised on this page, including the latest Bali Democracy Forum, ASEAN Summit and Senior Official Meeting, as well as other events and meetings like various bilateral meetings of Foreign Minister Natalegawa with his counterparts.

One interesting development is the recent post of the statement of British Foreign Secretary, William Hague, during the recent visit of President SusiloBambangYudhoyono to that country. Unlike previous posts which dominantly took the form of links to relevant news from Kemlu's official website, this feed is submitted as a complete statement and provided in Bahasa Indonesia as well as in English.

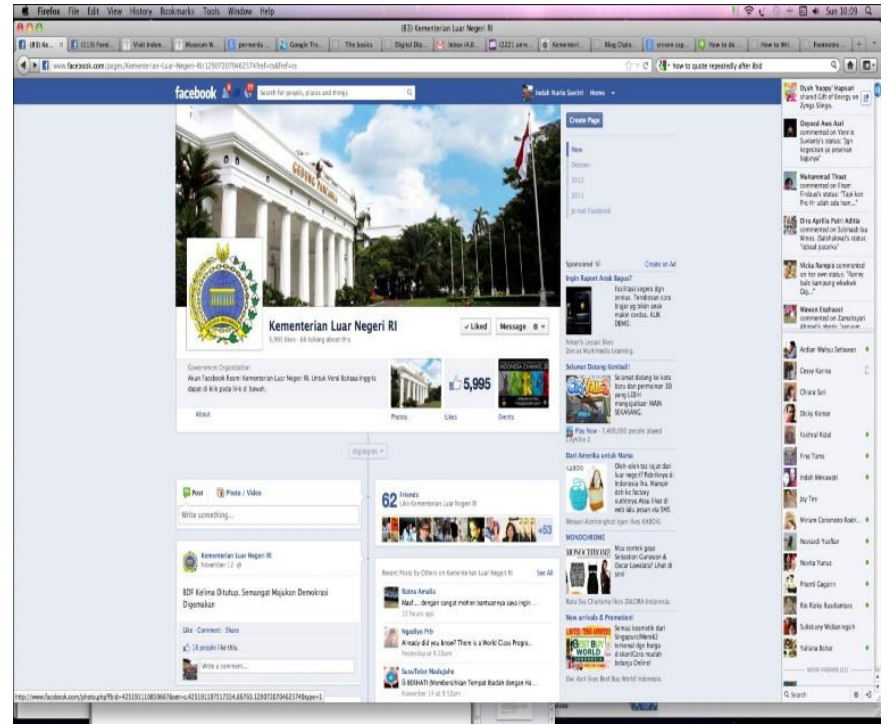

Picture 3: Official Facebook account of Kemlu

(source:http://www.facebook.com/pa ges/Kementerian-Luar-Negeri-RI)

Policies as well as information regarding high-profile issues, such as protection of Indonesian citizens abroad and international security and conflicts happening in Gaza Strip, Syria, Myanmar and other places, have been tweeted frequently. Moreover, in line with Kemlu's priorities, economic diplomacy is also highlighted, as business meetings and trade fairs, the visit of business sectors from various countries, and the signing of various trade agreements are among the feeds being tweeted. Getting more specifically on cultural diplomacy, efforts emphasizing people-to-people contacts and social cultural events, such as art and cultural scholarships, student exchanges, technical cooperation, cultural performances, Indonesian nights and many more, are also actively disseminated through Twitter. ${ }^{39}$

Beside the abovementioned Kemlu'sengagement, many Indonesian

\footnotetext{
${ }^{39}$ Kemlu RI, @Portal_Kemlu_RI, available at https://twitter.com/Portal_Kemlu_RI, accessed on October 15, November $10-18$, 2012.
} 
missions and embassies around the world manage their own Facebook or Twitter accounts. Statistics show that Indonesian Embassies in Amman, Beijing, Bern, Bucharest, Cairo, Canberra, Den Haag, London, Kuala Lumpur, Manila, Moscow, Singapore, Ottawa, Port Moresby, Washington D.C., and Yangon, among others, have actively engaged in these networking sites.

At personal level, many of Indonesian Ambassadors and diplomats have also utilized social media outlets as one of the tools to introduce and promote Indonesia abroad. Despite the fact that their accounts are initially set for personal use, some of the feeds broadcasted elements of Indonesian values, cultures and ideas, thus positively contribute to the conduct of Indonesian diplomacy, particularly economic and cultural diplomacy. Topics such as Indonesian Batik and traditional heritage, protection of Indonesian citizens abroad, and Indonesian economic potentials dominate the feeds. Some of those active Facebook users are, among others, Prianti Gagarin SinggihDjatmiko, Ambassador to Venezuela; LutfiRauf, Ambassador to Thailand; and Salman Al Farisi; Ambassador to United Arab Emirates. 40

Nevertheless, it is important to note that dissemination of information is just one dimensional way of communicating with constituents. Two-way dialogues are increasingly needed, if not demanded, by public, as

40 Observations on the abovementioned Facebook accounts were conducted for the period of October, 15-November, 18 in www.facebook.com. Many accounts owned and managed by Indonesian diplomats are also actively promoting Indonesia, but the writer limits the observations on the three accounts submitted. part of the increasing global culture of transparency and accountability.

At this point, Kemlustill has to further develop the 2.0 aspect of this communication, the interactive nature between Kemluand public. The establishment of interactive dialogues with public is still limited and we cannot deny that public complaints are still lodged to this institution for not being 'responsive'. For simple examples, in some of the feeds in Facebook, users were frequently asking about the result of a competition held by Kemlu as well as updated information about scholarships which were not swiftly responded by the administrator. Moreover, most of the "followers" or "friends" are Indonesian diasporas or Kemlu's big family. Although it is important to engage with Indonesian constituents, outreach programs focusing on foreign citizens can be further strengthened.

5 Strategie in maximizing social media to enhance Indonesia's economic and cultural diplomacy

With more foreign ministries, including Indonesia, lining up to embrace and integrate social media sites in their communication and public diplomacy, the question now is what measures Kemluhas to take in order to maximize the benefits derived from effective use of social media in enhancing economic and cultural diplomacy.

In order to carefully consider all relevant elements in this regard,internal factors, which consist of strengths and weaknesses; as well as external factors, - opportunities and threats, are identified herewith under:

\section{1). Internal Factors - Strengths}

Undoubtedly, there are several strengths that Kemlu has in relations to 
the use of social media in enhancing Indonesian diplomacy, which can be described as follows:

Many Indonesian diplomats are very familiar with social media. 'Digital divide' in terms of level of familiarity with these interactive platforms might be present, but the majority of diplomats have their accounts in at least one of the popular networking sites.

Dedicated directorates dealing with information and media, including multimedia, and public diplomacy have been established, along with the internal institutional reform within Kemlu. Further empowerment has to be conducted, nevertheless.

Well-established

infrastructures in Kemlu enable diplomats and other staffs to enjoy good internet connections at the office, thus facilitating them in using social media for official use.

2).Internal Factors - Weaknesses

Some weaknesses have also been identified, which, among others, consist of:

The absence of clear and formal policies regarding the use of social media in the conduct of diplomacy poses a certain level of uncertainty for those who want to utilize these outlets. Limited human resources who are in charge of Kemlu's engagement in social media hamper its active participation and swift responses, particularly with numerous accounts, pages and sites to manage.

Insufficient budget allocation for further development and active engagement of Kemlu through social media hinders its ability to introduce innovative approach and adapt to the dynamics of this digital diplomacy.

\section{3). External factors - Opportunities}

As previously mentioned in Chapter II, the opportunities present, among others, can be described as follows:
Social media sites provide spontaneous and direct interaction with friends, families, colleagues and even strangers. Despite time differences and vast geographical space, they enable people to get in touch with a large number of people instantly, as long as both parties have access to internet connections. This will help Kemlu build extensive networks and expand its public diplomacy effectively.

Social media helps spreading information easier, faster and farther, as showcased by Twitter and Facebook which reach a global audience in real-time.

Social media can be use as one of the analytical tools to get better and deeper understanding towards people from different cultures and backgrounds. Their perspectives and aspirations will help shaping the relevant policies and programs.

4). External Factors - Threats

When it comes to threats, the following factors have been identified as such:

As social media outlets are open platforms, engagement with them has the potential to be negative. Ill-fated users might divert or even destruct the outreach and interaction process between Kemlu and other users, as they post detrimental comments or inputs.

The risks of 'losing control' over certain issues and/or policies are imminent as public's responses can be unpredictable sometimes. Open discussions towards particular topics should ideally support the targeted goals set by Kemlu.

Different landscape of information societies and e-culture in various countries significantly impact the level of responsiveness and acceptability of people towards information disseminated through social media. Therefore 
With the identification of the abovementioned internal and external factors, the paper offers the following recommendation

\section{CONCLUDING}

From the deliberations given in the previous chapters and lesson learned from the practice of digital diplomacy by other countries, it is safe to conclude that digital diplomacy has indeed brought fundamental change in the way governments interact with public and social media, as one of the marvels of the advance of ITC, is regarded as one of the effective tools in disseminating ideas, policies, ideologies, and even political influence, to a wide sphere of mass public. But the use of social media is not, and cannot be, a substitute of traditional face-to-face diplomacy. It is also argued that while social media has not changed the objectives of foreign policy, it has somehow changed what people expect from the government.

The great potentials of the use of social media is yet to be optimized in promoting Indonesia's economy and cultural diplomacy. As social media's greatest contribution to public diplomacy occurs when it creates potential for continued engagement and dialogue, the need for understanding target audiences and conveying information in a longlasting and user-friendly ways is imperative.

Diplomats can definitely play more active roles in promoting economy and cultural diplomacy through social media. Either on personal level or in a formal setting, experiences show that many Indonesian diplomats depicting their personal passions and commitments towards Indonesian cultures, values and economic potentials, have positively attracted the attentions of public.
If managed well, the benefits of engaging these new media outlets can outweigh the costs, as well as the challenges and risks emerged from this interaction. For rather 'soft' or neutral issues such as those related to economy and cultural diplomacy, active engagement through social media will help promoting the ideas, policies, and events related to the issues at hand.

Clearly, our own ' $21^{\text {st }}$ century statecraft' is a work in progress. Even though ICT has yet to be fully embedded into the conduct of Indonesian diplomacy, but it is indeed a viable tool diplomats could use to further promote Indonesian economy and cultural diplomacy. Larger conceptual shift may be required with regard to the use of social media, but small steps involving formulation and implementation of effective strategies on embracing and integrating social media in the conduct of diplomacy will be a good start.

\section{RECOMMENDATIONS}

In order to maximize the role of social media in strengthening Indonesian economy and cultural diplomacy, the following recommendations can be further considered:

Clear and integrated policy on the use of social media in the conduct of diplomacy should be urgently developed and implemented. This will provide assurance and better guidance for diplomats in engaging him or herself with public through those networking channels. With this guidance, similar messages can also be broadcasted from all available outlets, amplifying Indonesia's national interests abroad. The dos and the don'ts in interacting with public through social media outlets need to be outlined in order to minimize diplomatic blunders.

There is a need to create an institutional framework that can take 
full advantage of new media, with an understanding that they should be vigilantly tailored to particular circumstances. If possible, a dedicated unit or a task force for digital diplomacy is established, with a clear mandate and job description which will facilitate its full engagement with public through social media and similar venues. If such unit is considered available, i.e. Subdirectorate of Multimedia, then it has to be further strengthened in all aspects.

Concerted efforts and close coordination between all related stakeholders within Kemlu as well as with other ministries and agencies need to be strengthened. As timesensitivity and responsiveness have to be maintained, measures must be taken in order ensure that necessary updates and responses are submitted timely.

Innovative strategies and creative approach need to be developed, offering incentives for users to loyally interact with Kemlu. Trivial quiz and contests regarding Indonesia economic potentials cultural heritages are worth considering. Further empowerment of bloggerdiplomat needs to be enhanced and similar creative engagement in less formal dialogue can be conducted.

The availability of reasonable resources, - in terms of human, infrastructures/ facilities well as budget, should be strengthened and maintained, in order to ensure the sustainability of the relevant strategies and programs.

Capacity building programs, in the forms of workshops and trainings relevant to the effective use of social media in public diplomacy should be conducted, involving as many diplomats as possible in order to have the common perspectives in this regard.

\section{REFERENCES}

Bain, Ben. "State Department Opens Up with Dipnote Blog," Federal Computer Week, September 27, 2007.

Bennet, Shea.The 10 Countries With The Most ActivesTwitter Users, 24 September 2012,

Boyd, Danah M., and Nicole B.Elisson, Social Network SitesDefinition, History, and Scholarship. Journal of Computer-Mediated Communication Vol. 13(2008) pp. $210-230$.

Ciolek,Melanie. "Understanding Social Media's Contribution to Public Diplomacy :How Embassy Jakarta's Facebook Outreach Illuminates the Limitations and Potential for the State Department's Use of Social Media," .

Esser, Victoria.“'Digital Diplomacy: A New Frontier of Diplomacy or Simply a Delusion?", September 24, 2012.

Furchgott, Roy. "State Department to Text Obama Speech," The New York Times, June 3, 2009.

Hanson, Fergus."Revolution @State: The Spread of EDiplomacy"Lowy Institute for International Policy,

Henry, Owen. "“Twitter Diplomacy” Engagement Through SocialMedia in 21 st Century Statecraft,"

Hill, David T. andKhrisnaSen, "The Internet in Indonesia's NeDemocracy", Democratization Vol 7 (1), 2000, pp. 119 - 136

Hounshell, Blake.The Revolution Will be Tweeted, Foreign Policy, July 2011, at 20,

Joseph, Sarah. "Social Media, Political Change, and Human Rights," 35 B.C. Int"l\& Comp. L. Rev. 145 (2012).

Kaplan, Andreas M., and Michael Haenlein, "Users of the world, unite! The challenges and 
opportunities of Social Media," Business Horizon Vol. 53, issue 1, $-68$.

January-February 2010, pp. 59

Kena, Megan. "Social Media: following EU public diplomacy and friending MENA", Policy Brief, European Policy Centre, July 2011,

Kietzmann, Jan

H., KristopherHermkens, Ian P. McCarthy, Bruno S.Silvestre, "Social media? Get serious! Understanding thefunctional building blocks of social media", Business Horizon (2011) Vol. 54, pp. 241 - 251,

Minister for Foreign Affairs Regulation Number 7 Year 2011 on the Organization and Procedures in the Ministry of Foreign Affairs.

Nye, Jr., Joseph S. "Public Diplomacy and Soft Power," Journal of the American Academy of Political and Social Science 616: 94 - 109.

Organisation for Economic Cooperation and Development (OECD), "Participative Web and User-Created Content: Web 2.0, Wikis and Social Networking" Vol. 18 (2007).

Phillips, Sarah."A brief history of Facebook".The Guardian(London).

Stockman, Sarah. "U.S. to Shifts Envoys to Developing Countries, "The New York Times", January 19, 2006,

Shirky, Clay."The Political Power of Social Media", 90 Foreign Affairs 28 , pp. 28 - 29.

"Transparency and Open

Government:Memorandum for the Head of Executive Departments and Agencies", the White House, January 2, 2009.

The American political scientist and author, Dr. Milton C. Cummings, offers this 14profound definition of cultural diplomacy, as cited by the Institute of Cultural Diplomacy 